\title{
Translation, cultural adaptation and reliability of the brazilian version of the Graded Wolf Motor Function Test in adults with severe hemiparesis
}

\author{
Tradução, adaptação cultural e confiabilidade da versão brasileira do \\ Graded Wolf Motor Function Test em adultos com hemiparesia grave
}

\author{
Natalia Duarte Pereira ${ }^{[a]}$, Luciane Vieira ${ }^{[b]}$, Fernanda Priscila Pompeu ${ }^{[b]}$, \\ Isabella De Souza Menezes ${ }^{[c]}$, Sarah Monteiro Dos Anjos ${ }^{[c]}$, Angélica Cristiane Ovando ${ }^{[\mathrm{d}] *}$ \\ [a] Universidade Federal de São Carlos (UFSCar), São Carlos, SP, Brazil \\ [b] Centro Universitário Nossa Senhora do Patrocínio (CEUNSP), Itu, SP, Brazil \\ [c] Universidade de São Paulo (USP), São Paulo, SP, Brazil \\ [d] Universidade do Estado de Santa Catarina (UDESC), Florianópolis, SC, Brazil
}

\begin{abstract}
Introduction: The Graded Wolf Motor Function Test (GWMFT) was developed as a modification of the Wolf Motor Function Test (WMFT), designed to address moderate-to-severe upper-extremity motor impairment, consequent to a stroke or brain injury, by combining time and quality of movement measures in both isolated movements and functional tasks. Objectives: To translate and adapt the GWMFT form and instructions manual to Brazilian Portuguese and evaluate the inter-rater reliability. Materials and methods: Ten
\end{abstract}

* NDP: PhD student, e-mail: nat_duarte@yahoo.com.br LV: grad, e-mail: vieira_luciane@hotmail.com FPP: Specialist, e-mail: fezinha_butterfly@hotmail.com ISM: MSc, e-mail: isa_menezes@yahoo.com.br SMA: MSc, e-mail: sarah.m.anjos@gmail.com ACO: PhD, e-mail: angecris@yahoo.com.br 
individuals, mean age $53.2 \pm 11.39$ (range: 28-72) years and a mean time since stroke onset of $82.5 \pm 85.83$ (16-288) months participated in the study. After translation and cultural adaptation, two independent evaluators, based on the instructions manual information, administered GWMFT. Video observations were used to rate the time and the compensatory movements in the Functional Ability Scale (FAS). Intra-class Correlation Coefficients (ICCs) and Bland-Altman plots were calculated to examine the inter-rater reliability for performance time and FAS. Results: The translated and adapted version obtained a total ICC inter-rater time 0.99 (0.95-1.00), showing less reliability in the task of lifting a pen, with ICC $=0.71(-0.15-0.93)$. The ICC of the total FAS was $0.98(0.92-0.99)$ and the task of elbow extension has shown the lowest ICC rate = 0.83 (0.31-0.96). Conclusion: The GWMFT scale reliability proved to be appropriate to evaluate the paretic upper limb in individuals with chronic hemiparesis post severe stroke.

Keywords: Hemiplegia/hemiparesis. Reproducibility of results. Upper Extremity. Stroke.

\section{Resumo}

Introdução: $O$ Graded Wolf Motor Function Test (GWMFT) foi desenvolvido por meio de uma modificação do Wolf Motor Function Test (WMFT) para avaliar o membro superior de adultos com hemiparesia grave combinando medidas de tempo e qualidade de movimento em movimentos isolados e tarefas funcionais. Objetivos: Traduzir e adaptar para a língua portuguesa o formulário e o manual de aplicação do GWMFT e avaliar a confiabilidade interavaliadores. Materiais e Métodos: Participaram do estudo 10 indivíduos com média de idade 53,2 \pm 11,39 (28-72) anos que apresentavam hemiparesia grave (Fugl-Meyer $\leq 30$ ) com cronicidade de 82,5 \pm 85,83 (16-288) meses, função cognitiva preservada e ausência de dupla hemiparesia. Após a tradução e adaptação cultural da escala, o GWMFT foi aplicado por dois avaliadores utilizando as informações do manual de aplicação e a filmagem das tarefas foi utilizada para cotar o tempo e qualidade de movimento pela Escala de Habilidade Funcional adaptada (EHF). A confiabilidade interavaliador do tempo e EHF do movimento foram avaliadas pelo Coeficiente de Correlação Intraclasse (CCI) e pelo método Bland-Altman. Resultados: Com a aplicação da versão traduzida e adaptada obteve-se CCI interavaliador total do tempo de 0,99 (0,95-1,00), apresentando menor confiabilidade na tarefa de levantar caneta, com CCI de 0,71 (-0,15-0,93). O CCI da EHF total foi de 0,98 (0,92-0,99) sendo a tarefa extensão do cotovelo com menor índice de CCI =0,83 (0,31-0,96). Conclusão: A confiabilidade da escala GWMFT demonstrou-se adequada para avaliar o membro superior parético com acometimento grave em indivíduos com hemiparesia crônica pós AVC.

Palavras-chave: Hemiplegia/hemiparesia. Reprodutibilidade dos testes. Extremidade Superior. Acidente Vascular Cerebral.

\section{Introduction}

About $70 \%$ of the patients with stroke, who present upper limb paresis remain disabled (1-3), even patients with mild physical dysfunction. The most common difficulties presented by stroke patients are slower reach and grasp movements, excessive compensatory trunk movements and grasp and pinch function reduction $(4,5)$.

Instruments that measure the efficacy of rehabilitation are deeply needed. Systematic and reliable assessments provide information that influence clinical decisions. They are essential for sensory motor function, functional ability and quality of life evaluation, and to avoid self-report subjectivity (6).

Many instruments have been developed to evaluate different functional and sensory motor aspects of the upper limb of patients with stroke. These tools can be used in clinical practice, diagnosis, prognosis and treatment effects (7-11). One of them is the Wolf Motor Function Test (WMFT) (12), developed by Dr Steven Wolf from Emory University School of Medicine in 1989. It was initially used to measured Constraint Induced Movement Therapy (CIT) efficacy (13) in hemiparetic patients. 
The WMFT was modified until its final version that contains 17 tasks that demand many active movements of the shoulder, elbow, wrist and fingers and functional tasks with different levels of complexity (fine and gross motor skills) (12-14). This tool has been translated and adapted into the Portuguese language and the Brazilian version presented good intra and inter-examiner reliability (9). This scale has been appointed as an important tool for the characterization of upper limb motor ability in high functional patients in a chronic phase after stroke and Traumatic Brain Injury (TBI). However, the WMFT has a limited use in low functional chronic patients with stroke or TBI. This occurs mainly because these patients are able to perform less than a half of the tasks $(12,15-18)$.

Thus, only a small group of patients has the necessary motor ability to perform all WMFT tasks. Consequently, modified or graded versions of the WMFT have been developed for patients with low upper limb functionality. A version with 13 tasks, 8 from the original version, was developed. In this version, all tasks can be performed in two different ways, according to the levels of complexity, and this justifies the name Graded Wolf Motor Function Test (GWMFT) (19).

Despite the fact that there are other upper limb paretic assessments translated and adapted for Portuguese, the GWMFT is the only one that combines measures of time and quality of movement of specific movements of as in functional tasks applied to patients with moderate to severe motor impairment. For each task, patient's performance is evaluated by the time of execution and the quality of movement, according to the Functional Ability Scale (FAS). The other validated and widely used tests in Brazil, such as the Test d'Évaluation des Membres Supérieurs of Personnes Âgées (TEMPA) (7) and Fugl-Meyer (11), only evaluate the function and movement components, respectively.

In Brazil there is no instrument to evaluate the activity of upper extremity in severely affected patients. Internationally accepted instrument, translated and validated into our language are essential to enable objective assessment of the burden of stroke in our population. Languages differ much from each other and therefore traits described in one language may not correspond to another (20). Thus the process of a structured translation and cultural adaptation is necessary. Along this process, the evaluation of psychometric properties attests to the quality of the translated instrument (21).

Thus, the aim of this study was to translate into Brazilian Portuguese, perform the cross-cultural adaptation and assessed the inter-rater reliability of the Graded Wolf Motor Function Test (GWMFT), in order to qualify and quantify the motor skills of individuals with severe upper limb paresis.

\section{Materials and Methods}

The translation, adaptation and reliability study of an instrument of motor skill assessment of patients with severe paresis of the upper limb, the GWMFT, was conducted as described below.

\section{Participants}

The study was conducted with 10 participants of the Clínica Escola do Centro Universitário Nossa Senhora do Patrocínio (CEUNSP). The mean age was $53.2 \pm 11.39(28-72)$ years, six males and four females, not randomly and intentional selected. The included subjects had severe chronic hemiparesis (more than six months post-stroke), with a mean lesion time of $6.9 \pm 6.5$ years and preserved cognitive function (Table 1). They were excluded if they presented with bilateral hemiparesis or other diseases affecting the musculoskeletal system. This project was approved by our institutional Ethics Committee $\left(\mathrm{N}^{\circ} 231 / 2012\right)$ and all participants signed an informed consent form.

Patients that presented a score below 30 on the Fugl-Meyer test were considered severely impaired and with preserved cognitive function, according to the cutoff points suggested by Brucki et al (22), were included.

Translation and cultural adaptation

The translation of the manual and the form was carried out with consent of the original author. Two bilingual translators, whose native language was Portuguese, translated the form and manual of the GWMFT into Portuguese. 
Table 1- Subjects' characteristics

\begin{tabular}{ccccccc}
\hline Subjects & Age (years) & Gender & $\begin{array}{c}\text { Time of } \\
\text { Lesion (years) }\end{array}$ & Fugl-Meyer UL & $\begin{array}{c}\text { Mini Mental } \\
\text { State } \\
\text { Examination }\end{array}$ & Affected Side \\
\hline 1 & 28 & $\mathrm{~F}$ & 2.7 & 28 & 25 & $\mathrm{R}$ \\
2 & 52 & $\mathrm{M}$ & 15 & 27 & 24 & $\mathrm{R}$ \\
3 & 59 & $\mathrm{~F}$ & 24 & 12 & 24 & $\mathrm{~L}$ \\
4 & 48 & $\mathrm{M}$ & 2.8 & 27 & 26 & $\mathrm{R}$ \\
5 & 55 & $\mathrm{M}$ & 1.9 & 30 & 25 & $\mathrm{~L}$ \\
6 & 60 & $\mathrm{~F}$ & 5.2 & 20 & 24 & $\mathrm{R}$ \\
7 & 56 & $\mathrm{M}$ & 5 & 8 & 20 & $\mathrm{R}$ \\
8 & 72 & $\mathrm{M}$ & 1.3 & 20 & 27 & $\mathrm{R}$ \\
9 & 46 & $\mathrm{~F}$ & 4.5 & 25 & 25 & $\mathrm{R}$ \\
10 & 56 & $\mathrm{M}$ & 6.25 & 27 & 27 & $\mathrm{R}$ \\
\hline Average $\pm \mathrm{SD}$ & $53.2 \pm 11.39$ & $6 \mathrm{M} / 4 \mathrm{~F}$ & $6.9 \pm 6.5$ & $24.2 \pm 10.23$ & $25.2 \pm 3.42$ & $8 \mathrm{R} / 2 \mathrm{~L}$ \\
\hline
\end{tabular}

Note: $\mathrm{UL}=$ Upper Limb; $\mathrm{M}=$ male; $\mathrm{F}=$ female; $\mathrm{R}=$ Right; $\mathrm{L}=\mathrm{Left} ; \mathrm{SD}=$ Standard Deviation.

One of the translators was aware of the goals and concepts that were being evaluated by the instrument and was trained by the group of authors from the last version of the test at the University of Alabama (UAB), Birmingham, Alabama, USA. The other translator had no prior knowledge of the intention and concepts of the instrument. Both translators worked independently without interfering in the translation process. The synthesis of the two translated versions was conducted during a meeting of both translators and the main researcher. A single final version translated into Portuguese was obtained by comparing the original version and both translations. From this single version, two different qualified translators carried out a back translation. Neither had prior knowledge of the intent and concepts of the material and performed the back translation independently. At this time, we evaluated whether the translated version reflected the same original content. The process of the translation and back translation of the final version of the instrument was submitted to review by a panel of expert judges, composed of two physical therapists with experience in stroke rehabilitation and fluent in both languages and an occupational therapist trained in Alabama for CIT application. This committee discussed the clarity, relevance and equivalence between the translated, back translated versions and the original version of the GWMFT. The back translated version was sent to the approval of the UAB group, which considered that the original version concepts were maintained. The translated manual can be obtained by request. The Functional Ability Scale (FAS) used to quantify the quality of movement, has been translated previously (9) during the WMFT translation to Portuguese. Detailed information about compensatory movement, incoordination and details for a higher clarity of movement quality items were added. These modifications were carried out with the consent of the original authors and maintained in the Brazilian GWMFT version.

\section{GWMFT application}

Two examiners, who read the manual without prior training and discussed all doubts with a trained professional, applied GWMFT. Application was performed with approximately two weeks between evaluators.

The test consists of performing standardized and adapted 13 tasks with patients with severe hemiparesis (Table 2). According to the manual, each task 
is described and shown twice by the examiner, the first demonstration is performed slowly and second quickly. Participants are told not to train the task while it is being explained, and to execute them as quickly as possible. The participant should only begin the tasks when the examiner uses the verbal command: "Ready, set, go!"

During task execution, filming and timing of each task was performed to improve scoring of the quality of movement. Filming position was established in accordance to the manual and varied for every task. Tasks are divided into two levels, A and B. The first one, level A, is more difficult and should be performed by all participants. If the individual cannot finish the task in 60 seconds, the examiner should apply the level B. For this level, the tasks are subjected to minor adaptations and the individual has over 60 seconds to perform them.

Table 2 - Inter-rater Reliability for the Application of GWMFT

\begin{tabular}{|c|c|c|c|c|}
\hline Task & & Evaluator 1 & Evaluator 2 & $\begin{array}{l}\text { ICC consistence } \\
\text { (Cl 95\%) }\end{array}$ \\
\hline \multirow{2}{*}{ 1. Forearm to Table } & Time Average & 48.2 & 38.01 & $0.86(0.43-0.96)$ \\
\hline & Average FAS & 3.3 & 3.2 & $0.98(0.92-0.99)$ \\
\hline \multirow{2}{*}{ 2. Forearm to Box } & Time Average & 68.4 & 44.5 & $0.84(0.37-0.96)$ \\
\hline & Average FAS & 2.3 & 3 & $0.86(0.45-0.97)$ \\
\hline \multirow{2}{*}{ 3. Extend Elbow } & Time Average & 93.4 & 100.6 & $0.96(0.82-0.99)$ \\
\hline & Average FAS & 1.6 & 1.7 & $0.83(0.31-0.96)$ \\
\hline \multirow{2}{*}{ 4. Extend Elbow (with weight) } & Time Average & 76 & 92.8 & $0.92(0.70-0.98)$ \\
\hline & Average FAS & 2 & 1.6 & $0.94(0.74-0.98)$ \\
\hline \multirow{2}{*}{ 5. Hand to Table } & Time Average & 38.4 & 38.1 & $1.00(1.00-1.00)$ \\
\hline & Average FAS & 3.4 & 3.1 & $0.98(0.90-0.99)$ \\
\hline \multirow{2}{*}{ 6. Hand to Box } & Time Average & 62.3 & 61.8 & $1.00(1.00-1.00)$ \\
\hline & Average FAS & 2.5 & 2.2 & $0.98(0.93-1.00)$ \\
\hline \multirow{2}{*}{ 7. Reach and Retrieve } & Time Average & 61.9 & 50.7 & $0.93(0.74-0.98)$ \\
\hline & Average FAS & 2.7 & 2.6 & $0.97(0.87-0.99)$ \\
\hline \multirow{2}{*}{ 8. Moving Foam Stick } & Time Average & 77.9 & 63.2 & $0.72(-0.12-0.93)$ \\
\hline & Average FAS & 1.9 & 2 & $0.84(0.36-0.96)$ \\
\hline \multirow{2}{*}{ 9. Lifting Washcloth } & Time Average & 109.3 & 110.2 & $0.87(0.49-0.97)$ \\
\hline & Average FAS & 1.1 & 1.1 & $0.96(0.84-0.99)$ \\
\hline \multirow{2}{*}{ 10. Flip Light Switch } & Time Average & 102.9 & 97.9 & $0.87(0.49-0.97)$ \\
\hline & Average FAS & 1.3 & 1.5 & $0.91(0.65-0.98)$ \\
\hline \multirow{2}{*}{ 11. Lift Pen } & Time Average & 100.9 & 96.1 & $0.71(-0.15-0.93)$ \\
\hline & Average FAS & 1.4 & 1.3 & $0.98(0.92-0.99)$ \\
\hline \multirow{2}{*}{ 12. Lift Cotton Balls } & Time Average & 112.3 & 102.2 & $0.84(0.36-0.96)$ \\
\hline & Average FAS & 1.1 & 1 & $0.89(0.57-0.97)$ \\
\hline \multirow{2}{*}{ 13. Lift Basket } & Time Average & 73.2 & 56 & $0.81(0.25-0.95)$ \\
\hline & Average FAS & 2.3 & 1.9 & $0.95(0.79-0.99)$ \\
\hline \multirow{2}{*}{ Total } & Time Average & 78.7 & 73.2 & $0.99(0.95-1.00)$ \\
\hline & Average FAS & 2.06 & 2.02 & $0.98(0.92-0.99)$ \\
\hline
\end{tabular}

Note: ICC = Interclass Correlation Coeficient; $\mathrm{Cl}=$ Confidence Interval; FAS = Functional Ability Scale. 
Each task is scored according to the time required to complete the tasks. For level B, 60 seconds of the level A task (that has not been completed), is added to the final time of the Level B execution. For level A, the score applied is exactly the time required to complete the task. If the subject is unable to accomplish the task at both levels, he receives a score of 121 seconds. Participants should continue the task to reach level B during 60 seconds, but can be interrupted at any time before 60 seconds if, in the opinion of the examiner, there is no condition of task execution.

Final scores of each participant are the average time required to execute all tasks. Quality movement measurement was carried out by evaluating the film of each task, following the FAS. Movements were scored from 0 to 3 for level B and 4 to 7 for level A (Table 3). At the end of the film evaluation of all tasks, the quality of movements of each patient is obtained by averaging the scores of all tasks in the FAS.

Table 3 - Adapted Functional Ability Scale (9)

\begin{tabular}{|c|c|c|c|}
\hline \multicolumn{4}{|c|}{ Adapted Ability Functional Scale (FAS) } \\
\hline \multirow{4}{*}{$\frac{\infty}{\Phi}$} & 0 - No attempt with the involved arm. & $\begin{array}{l}\text { 4- Does attempt, but requires assistance of the evalu- } \\
\text { ator for minor readjustments or change of position, } \\
\text { or requires more than two attempts to complete, or } \\
\text { accomplishes very slowly. Can have influence of ab- } \\
\text { normal synergic movements or is accomplished with } \\
\text { excessive trunk, head or upper limb compensation or } \\
\text { lack of proximal control and fine motor skills. In bilat- } \\
\text { eral tasks, the upper limb being tested can be used like } \\
\text { a non-dominant hand only. }\end{array}$ & \multirow{4}{*}{ 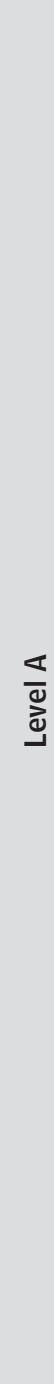 } \\
\hline & $\begin{array}{l}\text { 1- Involved arm does not participate functionally; } \\
\text { however, attempt is made to use the arm. In uni- } \\
\text { lateral tasks the uninvolved extremity may be used } \\
\text { to move the involved extremity and/or there is ab- } \\
\text { normal synergic movement or incoordination. }\end{array}$ & $\begin{array}{l}\text { 5- Does, but movement is performed slowly, and/ } \\
\text { or with effort, and/or with excessive compensatory } \\
\text { movements. There is influence of abnormal syner- } \\
\text { gic or compensatory and primitive patterns of grasp, } \\
\text { moderate incoordination and lack of fine movements } \\
\text { and resistance activities are done with difficulty. }\end{array}$ & \\
\hline & $\begin{array}{l}\text { 2- Does, but requires assistance of uninvolved } \\
\text { extremity for minor readjustments or change of } \\
\text { position, or requires more than two attempts to } \\
\text { complete, or accomplishes very slowly. Influence } \\
\text { of abnormal synergic movement or is accom- } \\
\text { plished with trunk, head or contralateral upper } \\
\text { limb compensation or lack of proximal trunk } \\
\text { control and fine motor skills. In bilateral tasks, } \\
\text { the tested upper limb can be used like a "second } \\
\text { hand". }\end{array}$ & $\begin{array}{l}\text { 6- Does; movement is close to normal, but slightly; } \\
\text { may lack precision, fine coordination or fluidity. }\end{array}$ & \\
\hline & $\begin{array}{l}\text { 3- Does, but movement is performed slowly, and/ } \\
\text { or with effort, and/or with excessive compensa- } \\
\text { tory movements. There are synergic and com- } \\
\text { pensatory movements with primitive patterns of } \\
\text { grasp, lack of fine movements and resistance } \\
\text { activities are done with difficulty. }\end{array}$ & $\begin{array}{l}\text { 7- Does; movement appears to be normal }{ }^{*} \text {. Fluidity } \\
\text { and coordination, speed similar to normal. }\end{array}$ & \\
\hline
\end{tabular}

Note: $\left(^{\star}\right)$ To be normal, the less affected upper limb can be used as a reference to be compared, and dominance before illness has to be considered too. 


\section{Statistical analysis}

Intra-class Correlation Coefficients (ICCs) with Confidence Intervals (CI) of 95\% were calculated to assess inter-rater reliability for performance measures of time and FAS.

Reliability in time performance was conducted to see if the two examiners had the same criteria to consider the beginning, the end, as well as the non-execution of the task and the reliability of the quality of movement to verify the perception of compensation for each evaluator during the execution of tasks. The following classification was adopted for ICC values: weak agreement, ICC < 0.04; moderate agreement, ICC > 0.04 and < 0.75; and excellent agreement, ICC > $0.75(23,24)$.

The ceiling and floor effects were calculated for GWMFT and each individual task: the percentages of scores that are grouped in the higher scores and lower, respectively. Values greater than $20 \%$ were considered significant. The presence of a high ceiling effect indicates a limited capacity of an instrument for individual discrimination (24). For a more detailed analysis of the possible differences in the scores of the two observers, a plot of the Bland and Altman was also carried out for total scores of time and EHF (10, $25)$. Significance level was set at $<0.05$.

\section{Results}

The agreement between raters was considered among moderate to excellent. The scores of the ICC were among 0.7 to 1.0 . The table 2 describes the time average and FAS average of each evaluator and the ICC inter-evaluator for each task and for total scores of the test.

No ceiling or floor effects were found when we considered the total scores of FAS. The score averages of GWMFT correspond to $41 \%$ of the maximum score. However, when the individual tasks were analyzed, a floor effect of $30 \%$ was observed for tasks 7 to 13 .

Bland and Altman analyses plot was used. In FAS, there is no significant difference between both evaluations, and the limits of agreement were 12 and $13.6 \%$ of variation of scales. Equally, the difference between raters in the item "time" was almost zero.
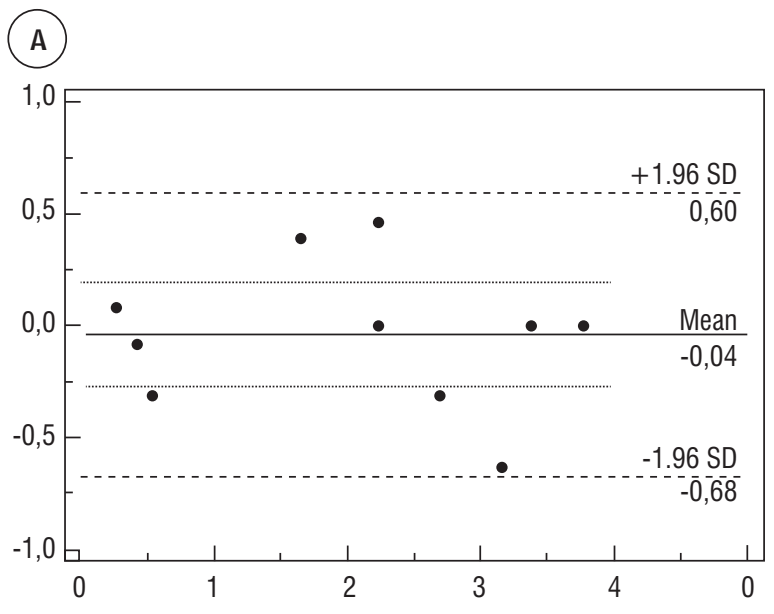

Mean of Inter-rater functional ability scale (FAS)
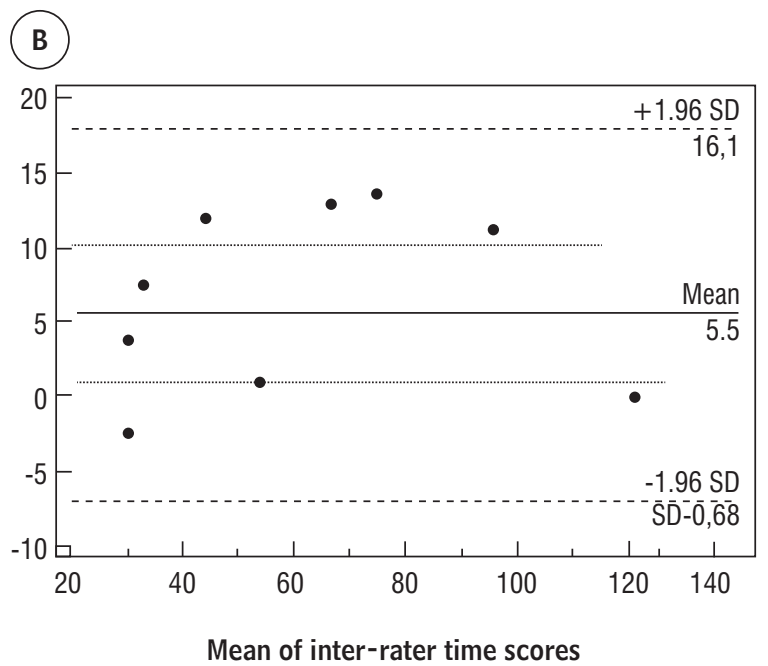

Mean of inter-rater time scores

Figure 1- Scatter-plots of the differences between the two GWMFT measurements and mean of total individual scores. $\mathrm{A}=$ Inter-rater Functional Ability Scale (FAS) scores; B = inter-rater time scores. The middle horizontal continuous black lines indicate the mean differences and the confidence intervals are presented in gray dotted line. The black dotted lines (more distant) indicate the upper and lower limits of agreement. 


\section{Discussion}

This study translated, adapted for the Portuguese language spoken in Brazil and determined the interrater reliability of GWMFT for individuals with severe impairment hemiparesis.

Inter-rater accordance of the translated and adapted version of GWMFT for performance in time was considered excellent by the total scores. There were 13 individual tasks analyzed, 11 had high interreliability index in time (ICC $>0.75$ ). The tasks hand to box and hand to table had higher reliability, reaching ICC time 1.00 (1.00 to 1.00) and ICC quality 0.98 (0.90-0.99). This occurred because the evaluators considered the execution and completion of the tasks satisfactory and the filming time enough to analyze the movement altogether, allowing a small error rate between evaluators. Also, participants had severe impairment and a change in performance of the task between both evaluations was not expected.

Seven of the 13 tasks were scored with 121 seconds at the first evaluation, and were, consequently, performed in the second evaluation and scored as level B. Probably, this could be as a result of a first contact of the patient with this test requiring the use of the paretic upper limb to fulfill the tasks.

A floor effect was also observed in 7 of 13 tasks. These tasks required increased fine motor distal movements. In a previous study using WMFT (9), $27 \%$ of participants had severe motor impairment (Fugl-Meyer $\leq 30$ ) and 27\% moderate (Fugl-Meyer $\leq 49$ ). In addition, in 12 of the 15 tasks applied participants scored 121 seconds for time execution (which characterizes an uncompleted task) and in 13 of the 15 tasks some participants scored 0 and 1 , which means no trials done and failed, respectively. Although the study (9) did not evaluate floor effect, it could have occurred in moderate and severe patients. This highlights the need for a more specific evaluation instrument for this population with severe hemiparesis.

Each WMFT task is applied with a running time of 120 seconds, and the patient must try and / or complete the task. Already GWMFT adapted tasks to patients with severe hemiparesis. These tasks are divided into two levels. If the individual does not complete the task in the first level (Level A), there is a brief period of time for which the evaluator to make the necessary adjustments to the second level (level B). This way, one advantage of GWMT would be the fact that there is both physical wear for implementing the tasks proposed.

All FAS scores, in individual tasks, had adequate inter-rater accordance (ICC > 0.84). These high reliability coefficients are probably due to the detailed description of the manual scoring form, as well as the test standardization features and the fact that the Brazilian version of the FAS is more detailed. Standardization and clarity of the information of assessment tools of administration manuals tends to reduce measurement errors (26). In the Brazilian version of the FAS, details about compensatory movements, abnormal synergy, proximal control and grasp primitive patterns were added. This information was based on the Quality of Movement Scale used for CIT that was created by the same CIT research group that developed the WMFT aiming to evaluate the results of this intervention (9). The final adapted version into Portuguese had the consent of the original authors to preserve the initial concept of the scale. Modifications aimed at evaluating movement changes that are commonly observed in individuals and that were not contemplated by the original scale. These modifications allow for a better classification and identification of these patients.

The most frequently found movement compensations were: lack of shoulder flexion, elbow extension, forearm supination, extension of the fingers and wrist, radial deviation and pinch. These compensations are the same as described by Wolf et al. (27) and contributed to a FAS low score. The authors suggest that GWMFT should be applied before CIT and after a certain period.

GWMFT includes a range of movements that can be useful as a clinical evaluation of patients with hemiparesis and also as a research tool. This scale evaluates UL functionality through quantitative variables, performance in time, coordination and fluidity of movement and other clinically relevant characteristics in individuals with severe motor impairment of the UL.

Compensatory trunk movements limit UL motor recovery after stroke (28-30) and the modified version of FAS explains and identify these items. It can help the therapist to decide on the best therapeutic approach. GWMFT presents a qualitative evaluation of the movement and this is an advantage compared with other scales that have the same goal (8). Evaluators with prior knowledge of patients' main 
compensations can score videos in order to obtain a reliable quality score (9).

Limitations of this study included a relatively small sample size and a small number of evaluators, which may limit result generalization. However, interevaluator reliability was considered excellent, even though untrained therapists applied the instrument, which suggested that the manual was clear enough to guide examiners during test administration. Further studies are necessary, with a larger number of evaluators from different areas of rehabilitation, as well as inclusion of subjects with moderate stroke.

\section{Conclusion}

The Brazilian version of GWMFT showed appropriate psychometric properties that suggest its applicability as a tool for motor performance measure of stroke patients with upper limb paresis, following the instructions manual carefully.

\section{References}

1. Wolf SL, Thompson PA, Winstein CJ, Miller JP, Blanton SR, Nichols-Larsen DS, et al. The EXCITE stroke trial: comparing early and delayed Constraint-Induced Movement Therapy. Stroke. 2010 0ct; 41(10):2309-15.

2. Dromerick AW, Edwards DF, Hahn M. Does the application of Constraint-Induced Movement Therapy during acute rehabilitation reduce arm impairment after ischemic stroke? Stroke. 2000 Dec; 31(12):2984-8.

3. Roger VL, Go AS, Lloyd-Jones DM, Benjamin EJ, Berry JD, Borden WB, et al. Heart disease and stroke statistics - 2012 update: a report from the American Heart Association. Circulation. 2012 Jan; 125(1):e2-e220.

4. Urton ML, Kohia M, Davis J, Neill MR. Systematic literature review of treatment interventions for upper extremity hemiparesis following stroke. Occup Ther Int. 2007; 14(1):11-27.

5. Michaelsen SM, Jacobs S, Roby-Brami A, Levin MF. Compensation for distal impairments of grasping in adults with hemiparesis. Exp Brain Research. 2004 Jul; 157(2):162-73.
6. Van der Putten JJ, Hobart JC, Freeman JA, Thompson AJ. Measuring change in disability after inpatient rehabilitation: comparison of the responsiveness of the Barthel index and the Functional Independence Measure. J Neurol Neurosurg Psychiatry. 1999; 66(4): 480-4.

7. Michaelsen SM, Natalio M, Silva A, Pagnussat A. Confiabilidade da tradução e adaptação do Test d'Évaluation des Membres Supérieurs de Personnes Âgées (TEMPA) para o português e validação para adultos com hemiparesia. Rev. Bras. Fisioter. 2008 Nov-Dec; 12(6):511-9.

8. Ferreiro K, Santos Rd, Conforto A. Psychometric properties of the Portuguese version of the Jebsen-Taylor test for adults with mild hemiparesis. Rev. Bras. Fisioter. 2010 Sept-Oct; 14(5):377-82.

9. Pereira ND, Michaelsen SM, Menezes IS, Ovando AC, Lima RC, Teixeira-Salmela LF. Reliability of the Brazilian version of the Wolf Motor Function Test in adults with hemiparesis. Rev Bras Fisioter. 2011 May-Jun; 15:257-65.

10. Pereira ND, Ovando AC, Michaelsen SM, Anjos SMd, Lima RCM, Nascimento LR, et al. Motor Activity LogBrazil: reliability and relationships with motor impairments in individuals with chronic stroke. Arq. Neuropsiquiatr. 2012 Mar; 70(3):196-201.

11. Michaelsen SM, Rocha AS, Knabben RJ, Rodrigues LP, Fernandes CGC. Translation, adaptation and interrater reliability of the administration manual for the Fugl-Meyer assessment. Rev. Bras. Fisioter. 2011 JanFeb; 15(1):80-8.

12. Wolf SL, Catlin PA, Ellis M, Archer AL, Morgan B, Piacentino A. Assessing Wolf Motor Function test as outcome measure for research in patients after stroke. Stroke. 2001 Jul; 32(7):1635-9.

13. Taub E, Uswatt G. Constraint-induced Movement Therapy: answers and questions after two decades of research. NeuroRehabilitation. 2006; 21(2):93-5.

14. Morris DM, Uswatte G, Crago JE, Cook EW 3rd, Taub E. The reliability of the Wolf Motor Function test for assessing upper extremity function after stroke. Arch Phys Med Rehabil. 2001 Jun; 82(6):750-5. 
15. Edwards DF, Lang CE, Wagner JM, Birkenmeier R, Dromerick AW. An evaluation of the Wolf Motor Function test in motor trials early after stroke. Arch Phys Med Rehabil. 2012 Apr; 93(4):660-8.

16. Fu TS, Wu CY, Lin KC, Hsieh CJ, Liu JS, Wang TN, Ou-Yang P. Psychometric comparison of the shortened Fugl-Meyer assessment and the streamlined Wolf Motor Function test in stroke rehabilitation. Clin Rehabil. 2012 Nov; 26(11):1043-7.

17. Lin KC, Hsieh YW, Wu CY, Chen CL, Jang Y, Liu JS. Minimal detectable change and clinically important difference of the Wolf Motor Function test in stroke patients. Neurorehabilitation Neural Repair. 2009 Jun; 23(5):429-34.

18. Ang JH, Man DW. The discriminative power of the Wolf Motor Function test in assessing upper extremity functions in persons with stroke. Int J Rehabil Res. 2006 Dec; 29(4):357-61.

19. Bonifer NM, Anderson KM, Arciniegas DB. ConstraintInduced Movement Therapy after stroke: efficacy for patients with minimal upper-extremity motor ability. Arch Phys Med Rehabil. 2005 Sep;86(9):1867-73.

20. Beaton DE, Bombardier C, Guillemin F, Ferraz MB. Guidelines for the process of cross-cultural adaptation of self-report measures. Spine. 2000 Dec; 15; 25(24):3186-91.

21. Schuster C, Hahn S, Ettlin T. Objectively-assessed outcome measures: a translation and cross-cultural adaptation procedure applied to the Chedoke McMaster Arm and Hand Activity Inventory (CAHAI). BMC Medical Research Methodology. 2010;10:106.

22. Brucki SMD, Nitrini R, Caramelli P, Bertolucci PHF, Okamoto IH, Ivan H. Sugestões para o uso do miniexame do estado mental no Brasil. Arq Neuropsiquiatr. 2003 Sep; 61(3B):777-81.

23. Fleiss JL, Levin BA, Paik MC. Statistical methods for rates and proportions. Hoboken, New Jersey: Wiley; 2003.

24. Mao HF, Hsueh IP, Tang PF, Sheu CF, Hsieh CL. Analysis and comparison of the psychometric properties of three balance measures for stroke patients. Stroke. 2002 Apr; 33(4):1022-7.
25. van der Lee JH, Beckerman H, Knol DL, de Vet HC, Bouter LM. Clinimetric properties of the Motor Activity Log for the assessment of arm use in hemiparetic patients. Stroke. 2004 Jun; 35(6):1410-4.

26. Sanford J, Moreland J, Swanson LR, Stratford PW, Gowland C. Reliability of the Fugl-Meyer assessment for testing motor performance in patients following stroke. Phys Ther. 1993 Jul; 73:447-54.

27. Wolf SL, Thompson PA, Estes E, Lonergan T, Merchant R, Richardson N. The EXCITE trial: analysis of "noncompleted" Wolf Motor Function Test items. Neurorehabil Neural Repair. 2012 Feb; 26(2):178-87.

28. Michaelsen SM, Dannenbaum R, Levin MF. Task-specific training with trunk restraint on arm recovery in stroke: randomized control trial. Stroke. 2006 Jan; 37(1):186-92.

29. Lima RC, Michaelsen SM, Nascimento LR, Polese JC, Pereira ND, Teixeira-Salmela LF. Addition of trunk restraint to home-based modified Constraint-Induced Movement Therapy does not bring additional benefits in chronic stroke individuals with mild and moderate upper limb impairments: a pilot randomized controlled trial. NeuroRehabilitation. 2014; 35(3):391-404.

30. Lima RC, Teixeira-Salmela L, Michaelsen SM. Effects of trunk restraint in addition to home-based modified Constraint-induced Movement Therapy after stroke: a randomized controlled trial. Int J Stroke. 2012 Apr; $7(3): 258-64$.

Received: 07/09/2013

Recebido: 09/07/2013

Approved: 04/27/2015 Aprovado: 27/04/2015 